\begin{abstract}
Aleksandra Szymil
Uniwersytet im. Adama Mickiewicza w Poznaniu

Wydział Filologii Polskiej i Klasycznej
\end{abstract}

\title{
Przepisać kulturę, czyli napisać slash
}

Fanfiction (inaczej fanfik, fik) to literacka twórczość fanów/fanek nawiązująca do jakiegoś tekstu kultury - najczęściej powieści, filmu lub serialu. W niniejszym artykule zajmę się analizą specyficznego podgatunku fanfikcji, pisanego prawie wyłącznie przez kobiety, jakim jest slash, czyli typ opowiadań skupiających się na homoerotycznych relacjach między mężczyznami.

W dyskursie akademickim slash uznawany jest bądź za gatunek romansowy (lub erotyczny), bądź wręcz pornograficzny. Postaram się zatem ukazać różnice i podobieństwa między slashem a romansem komercyjnym oraz opisać fanowską twórczość jako formę kobiecej pornografii - w kontekście feministycznym, a także wskazać, co odróżnia pisarstwo fanek od literatury gejowskiej.

\section{Slash a pornografia}

Przede wszystkim należy podkreślić, że chociaż teksty slashowe traktowane są przez wielu badaczy jako pornografia, to klasyfikowanie ich w ten sposób nie jest oczywiste. Sama definicja porno nie jest przecież pewna i stabilna. Również fanki nie odnoszą się do zaklasyfikowania slashu jako pornografii jednoznacznie. Chociaż część pisarek-amatorek utożsamia fiki z pornografią, to jednak w „oficjalnej” fandomowej terminologii dominują określenia takie jak smut czy prześmiewcze pron albo po prostu oznaczenie NC-17 lub mature. Natomiast dla drugiej części fanek dominującym elementem fika są fabuła lub uczucia, a nie aspekt pornograficzny. W takim rozumieniu zatem fik to coś więcej niż porno. Jednakże istnieje wiele tekstów, których cała, nawet bardzo złożona fabuła zorganizowana jest właśnie wokół seksualnego fetyszu - to ów fetysz determinuje wydarzenia i sposób kreacji świata. Nie brakuje też tekstów krótkich, opisujących jedynie scenę erotyczną, które pozornie w ogóle nie posiadają fabuły. Takie 
fiki nazywane są PWP (Porn Without Plot lub Plot? What Plot?). W przypadku fanfikcji jednakże brak fabuły jest de facto niemożliwy, autorka zawsze bowiem wprowadza w tekst postaci już ukształtowane, posiadające jakąś historię. Podsumowując - autorka i czytelniczka zawsze niejako zna już bohatera (zajmuje wobec niego jakąś emocjonalną postawę). Wbrew pozorom sprawa ma się nie inaczej w porno. Jak bowiem zauważa Lech Nijakowski, polemizując ze Slavojem Żiżkiem, który przeciwstawia „pokazywanie wszystkiego” (charakterystyczne dla pornografii) „właściwej fabule", również i w przypadku porno widz wcale nie zostaje sprowadzony jedynie „do roli sparaliżowanego obiektu-spojrzenia”, gdyż nawet:

Zubożony film pornograficzny jest umieszczany w świecie wyobraźni pornograficznej, gdzie wypełniane są rażące ze scenariuszowego i reżyserskiego punktu widzenia luki. Nagi akt pobudza w pełni wtedy, gdy wzbogaci się go o znaczenie. Oczywiście wiele zależy od wyrafinowania widza, ale nawet najmniej wyrobiony literacko konsument pornografii potrzebuje pewnej narracji pornograficznej ${ }^{1}$.

Adresatka ff nie musi sobie sama budować tej ramy interpretacyjnej dostaje ją w postaci konkretnego bohatera, zaś z punktu widzenia pisarki slash powoduje, że proste zepchnięcie do kategorii „tylko” porno staje się właściwie niemożliwe. Każdy, nawet najkrótszy tekst, poprzez wspomnianą emocjonalną bliskość fanek z bohaterami uruchamia proces aktywnego odbioru. To zwykłe dopowiadanie sobie historii czy dookreślanie biografii, które mają miejsce w przypadku komercyjnego porno, nabiera głębszego wymiaru - jest nawiązywaniem relacji z tą historią. Fanka czyta fika, nie tylko dlatego, że podoba się jej wizualnie dany bohater, fiki skoncentrowane są bowiem na relacji między bohaterami - tym samym fanka sięga po narrację, ponieważ interesuje ją dany związek [pairing].

Nijakowski zauważa jednak w pornografii coś, czego nie ma w slashu - mianowicie świat porno żyje krótko, kończy się wraz z orgazmem. Podobnie myśli Linda Williams, kiedy analizuje tzw. money shot. W slashu orgazm jest równie ważny, ale w fikach nic nigdy się nie kończy, zainteresowanie postacią z pornograficznego obrazu trwa dalej.

\section{Sadomasochizm, czyli pornokrytyka}

Specyficzną cechą slashowych fanfikcji jest ignorowanie kategorii płci biologicznej. Przykładem fanfiction niejako przełamujących stereotypowo rozumiane sex i gender są teksty prezentujące społeczeństwo oparte na

${ }^{1}$ L. M. Nijakowski, Pornografia. Historia, znaczenie, gatunki, Warszawa 2010, s. 281. 
wywodzącej się z fetyszystycznych praktyk seksualnych, niebiologicznej dynamice, jaką jest $D / s$ [Dominance/submission]. $D / s$ w tym rozumieniu to nie tylko typ zachowań erotycznych czy dobrowolnie przyjęty styl życia, lecz całościowa „orientacja seksualna”. W fikach tego rodzaju partnerem dominującym może być zarówno kobieta, jak i mężczyzna. Łączenie się w pary wyznaczone jest przez upodobanie/naturę (bardziej dominujący/a z bardziej uległym/ą), a nie płeć. Partnerzy „ulegli” postrzegani są zasadniczo jako usytuowani niżej w hierarchii społecznej i podlegli partnerom dominującym.

Podobny schemat funkcjonuje w fanfikcjach korzystających $\mathrm{z}$ fanonicznej interpretacji serialu The Sentinel (Gliniarz $w$ dżungli). Dynamika fabuły opiera się tu na relacji między obdarzonymi nadzwyczaj rozwiniętymi zmysłami, tzw. Sentinels - „strażnikami” i guides - „przewodnikami”. Sentinels posiadają wiele cech zwierzęcych, są też silniejsi i bardziej agresywni, ich rolą jest często chronienie zwykłych ludzi. Słabsi guides posługują się za to głównie empatią, by zapanować nad rozchwianymi „sentinelami”. Nawiązanie relacji strażnik - przewodnik może być niekonsensualne (głównie z perspektywy „przewodnika”). Guides wydzielają specyficzną woń, a ich zapach jest wyjątkowo atrakcyjny dla „sentineli”. Najrozkoszniej zaś pachną ci „przewodnicy”, którzy nie posiadają swojego „strażnika”. Efektem połączenia się „przewodnika” ze „strażnikiem” jest nierozerwalna niemal więź, którą przypieczętowuje stosunek seksualny.

Wszystkie stricte fetyszystyczne fanfiki, jak i popularność opowiadań wykorzystujących motyw fuck-or-die, a więc sex pollen czy aliens made them do it, w których to jakieś demoniczne siły doprowadzają do zbliżenia seksualnego między bohaterami (co nawiązuje poniekąd do folklorystycznych opowiadań o sukubach i inkubach, które rzekomo były odpowiedzialne za np. pozamałżeńskie ciąże), uwalniając ich tym samym od odpowiedzialności (a więc i poczucia winy), czy popularność fików dotyczących relacji niekonsensualnych, ukazują skomplikowanie tematyki ludzkiej seksualności i sposobu, w jaki traktuje ją współczesna kultura.

Przepracowywanie danych tematów w slashu zbliżone jest do roli, jaką dawniej odgrywała również pornografia (szczególnie np. XVIII-wieczna francuska powieść pornograficzna), która poprzez wykorzystywanie pewnych tematów czy ośmieszanie instytucji lub osób stanowiła rodzaj krytyki politycznej i filozoficznej ${ }^{2}$. Dopiero później, w XX wieku, nastąpiła komercjalizacja porno. Jako że fanfiction wyłączone jest z mechanizmów rynkowych, być może nadal zachowuje potencjał krytyczny. W fanfikcjach powraca bowiem to, co jest tabuizowane w dominującym dyskursie, a żeby przepracować tabu, należy je opowiedzieć.

${ }^{2}$ Zob. tamże. 


\section{Rozkosz uwolniona}

Jednakże w świadomości samych autorek slash nie ma wyłącznie wymiaru praktyki subwersywnej czy ideologicznie nacechowanej. Pisarki i czytelniczki fanfiction wielokrotnie podkreślają także aspekt stricte rozrywkowy tych opowiadań, zwłaszcza w odniesieniu do tekstów pornograficznych (które powoli zaczynają zresztą dominować w świecie fandomu). W tym przypadku slash służy zaspokojeniu seksualnemu, a lektura nastawiona jest na odczuwanie przyjemności. Slash dawałby to, czego odmawia kobietom komercyjna pornografia, czyli wolność od problemu tożsamości płciowej i seksualnej. Atrakcyjność slashowego porno wynikałaby z „oglądania seksualnej rozrywki, która różni się od tego, co robimy zazwyczaj”.

Podobnie, choć w odniesieniu do yaoi, o powodach pisania przez kobiety romansów homoerotycznych myśli Mark McLelland, gdy na postawione w tytule swojego artykułu pytanie Why are Japanese Girls' Comics Full of Boys Bonking odpowiada:

Dlaczego japońskie komiksy dla kobiet nie miałyby być pełne bzykających się facetów? Należy pamiętać, że „odgrywanie lesbijek” (rezupurei) w japońskim przemyśle seksualnym nie odnosi się wcale do dwóch kobiet występujących dla przyjemności mężczyzn, lecz transwestytów realizujących swoje lesbijskie fantazje z kobietami świadczącymi usługi seksualne. [...] W Japonii, jak wszędzie, mężczyźni zdają się mieć większe przyzwolenie na eksperymentowanie z seksualnością niż kobiety. Dlaczego męskie zainteresowanie lesbianizmem ma być uznane za oczywiste, a kobiece zainteresowanie męską homoseksualnością wymagać interpretacji? ${ }^{4}$.

Kobiece czytanie ff nabiera też wymiaru aseksualnej lesbijskości. Dostarczycielką rozkoszy jest bowiem inna kobieta, fanki w komentarzach pod opowiadaniem piszą jej o swoich reakcjach na erotyczny tekst (co zrobiło na nich największe wrażenie etc.), czasami bardzo bezpośrednio - komunikując np., iż dany komentarz został napisany jedną ręka. Bywa też, że fanki piszą pornograficznego fika razem lub wspólnie go czytają. Dale Rosenberg stwierdza wprost: „I, w ostateczności, piszę slash, bo jestem lesbijką i lubię podniecać kobiety".

Slash uruchamia zatem wszystkie pozytywne konteksty pornografii, zarazem jednak umożliwia uniknięcie przynajmniej części problemów, które niesie za sobą komercyjne dzieło filmowe:

${ }^{3}$ L.Williams, Hard-core. Władza, rozkosz i „szaleństwo widzialności”, Gdańsk 2010, s. 339 .

${ }^{4}$ M. McLelland, Why are Japanese Girls' Comics Full of Boys Bonking?, http://intensitiescultmedia.files.wordpress.com/2012/12/mclelland.pdf [dostep 1.11.2014]. Wszystkie tłumaczenia są autorskie. 
To jednoznacznie seksualna forma pisarstwa tworzona głównie przez kobiety i dla kobiet, a opisująca mężczyzn. Sposób budowania poczucia kobiecej seksualnej wspólnoty poprzez uprzedmiotowienie męskiego ciała, lecz nie samych mężczyzn. Nikt nie zostaje zmuszony do aktów seksualnych, nie powstają zdjęcia, nie ma prawdziwych osób. To fikcjonalne zawłaszczenie męskiej seksualności dla przyjemności kobiet i jako takie stanowi feministyczny rodzaj treści seksualnych ${ }^{5}$.

Wszystko to, co powraca w slashu, złagodzone jest przez aspekt fikcyjności. Williams odnotowuje, że kobiety oglądają dużo porno (40\% wszystkich konsumentów), muszą więc je wreszcie opowiedzieć po swojemu. Slash zdaje się doskonałą praktyką. Odrzucając mówienie o własnej rozkoszy za pomocą „mężczyzny brzuchomówcy”, w slashu kobiety same tworzą pornograficzne narracje, w których to mężczyźni podlegają ich kontroli, lecz bez upodlenia i dehumanizacji.

\section{Slash a romans}

Podobnie jak pornografia dyskurs na temat romansów jest mocno naznaczony poczuciem winy i wstydem. Czytanie romansu to czytanie próżniacze, dodatkowo kojarzy się z naiwną sentymentalnością, a romans sam w sobie bywa uznawany za gatunek antykobiecy.

Mimo tego (lub może - właśnie dlatego) wielu badaczy i badaczek upatruje w konwencjonalnym romansie podstawowy kontekst dla ff. Oba te gatunki łączy bowiem skupienie się na relacjach między postaciami i dominacja fabuły miłosnej. Dla wielu badaczy slash to po prostu kolejna forma kobiecej erotyki, wybierana przez fanki ze względu na możliwość opisania relacji partnerskiej między slashowanymi postaciami. W ten sposób rozpatrują slash np. Patricia Frazer Lamb i Diana L. Veith, które twierdzą ponadto, że slashowani bohaterowie stanowią figury androgyniczne, łączące w sobie cechy tradycyjnie męskie i kobiece? . Catherine Salmon i Don Symons uważają natomiast, że w slashu obaj protagoniści wspólnie „zarzynają smoki" i przeżywają różne przygody, gdyż w przeciwieństwie do romansu heteryckiego obie postaci mogą tu odgrywać rolę wojownika ${ }^{8}$.

${ }^{5}$ D. Rosenberg, Confessions of a Lesbian Feminist Slasher, „Off Our Backs” 2007, October.

${ }^{6}$ L. Williams, Hard-core..., s. 248.

7 P. F. Lamb, D. L. Veith, Romantic Myth, Transcendence, and Star Trek Zines, [w:] Erotic Universe. Sexuality and Fantastic Literature (Contributions to the Study of Science Fiction and Fantasy), ed. D. Palumbo, New York 1986, s. 235-255.

${ }^{8}$ C. Salmon, D. Symons, Slash fiction and Human mating Psychology, „The Journal of Sex Research” 2004, nr 1, s. 94-100. 
Tym samym tropem idą - w Textual Poachers - Henry Jenkins (upatrując w slashu „ostatnią linię oporu” wobec braku dostępnych w mediach kulturowych toposów relacji partnerskiej) oraz Constance Penley ${ }^{9}$ i Joanna Russ $^{10}$. Wszyscy ci badacze dostrzegają w fikach tego typu możliwość osiągnięcia romantycznej utopii.

W takim rozumieniu zainteresowanie samym slashem byłoby wyrazem zniechęcenia do popularnego romansu „heteryckiego”, uznanego za gatunek wyczerpany. Pozornie niewinne historie tego rodzaju zdają się obecnie wzbudzać niepokój wielu - wszakże dość uświadomionych - czytelniczek. Dostrzegają one w tych narracjach opakowane w wizję romantycznej miłości opowieści o związkach ukonstytuowanych na zniewoleniu, przemocy czy rezygnacji przez kobietę z własnego ja. Podsumowując - o relacjach, których wcale nie chciałyby same doświadczyć. Świat fikcyjny w tym przypadku nie daje zatem czytelniczkom ani możliwości spełnienia fantazji, ani możliwości ucieczki od realnych problemów. Fikcja bowiem okazuje się jedynie przekształceniem świata rzeczywistego wraz z zawartymi w nim zagrożeniami, co albo całkowicie uniemożliwia czerpanie przyjemności z lektury, albo przynajmniej je utrudnia, poprzez wzbudzenie poczucia winy. Czytelniczka ma świadomość problematyczności przeczytanej historii. Przyjemność staje się więc grzeszna. Jednak już wykorzystanie tego samego schematu fabularnego, ale w odniesieniu do związku dwóch mężczyzn, ponownie częściowo uwalnia czytelniczkę, pozwalając jej cieszyć się dobrze znanym tekstem i rozpoznawaniem zawartych w nim klisz, lecz bez całkowitej identyfikacji (w tym autorefleksji) i poczucia winy. Stąd popularne przepisywanie fabuł zaczerpniętych z komedii romantycznych, Harlequinów czy nawet filmów Disneya lub klasycznych baśni, z zastąpieniem heroiny postacią męską. Taki zabieg w swoisty sposób parodiuje schematy heteroseksualnych romansów, ukazuje też sztuczność podziału na role płciowe. Zarazem jednak po trosze reprodukuje heteronormatywny schemat.

Część badaczek dostrzega jednak wiele rozbieżności między romansem a slashem. Kustritz zauważa, że tak jak w romansie dominował model idealnej bohaterki, w slashu relacja między protagonistami oparta jest głównie na fascynacji intelektualnej i duchowej. Związek rozwija się z początkowej przyjaźni, a sami bohaterowie nie są wcale idealni, lecz autorka-fanka wręcz specjalnie podkreśla ich wady ${ }^{11}$. Badaczka tylko częściowo ma rację. Współczesny slash wprowadza więcej możliwości niż przywołany przez Kustritz tzw. buddyslash,

${ }^{9}$ C. Penley, Brownian Motion: Women, Tactics, and Technology, [w:] Technoculture, eds. C. Penley, A. Ross, Minneapolis 1991, s. 35-161.

${ }^{10} \mathrm{~J}$. Russ, Pornography by Women for Women, with Love, [w:] tejże, Magic Mommas, Trembling Sisters, Puritans \& Perverts, New York 1985.

${ }^{11}$ A. Kustritz, Slashing the Romance Narrative, „The Journal of American Culture” 2003, nr 3, s. 378. 
istnieje też chociażby powerslash (relacja oparta na nierównym statusie postaci - nauczyciel - uczeń, pracodawca - pracownik, pan - podwładny etc.) czy enemyslash (relacja między antagonistami) ${ }^{12}$. Kustritz w swoim artykule skupia się jednak na analizie „starego” (sprzed ery Internetu) fandomu, jakim jest Star Trek, dlatego też schemat „od przyjaźni do miłości” jest dla niej schematem najważniejszym, z niego bowiem de facto rozwinął się właśnie slash. Co więcej, w przypadku wielu fandomów, podobnie jak w konwencjonalnym romansie, często bohaterowie wcześniej się nie znają (casus fików typu AU - alternative universe), a pierwsze spotkanie wskazuje na natychmiastową fascynację seksualną. Często też autorki upiększają swoich - kanonicznie nie zawsze przystojnych - bohaterów. To, co w dziele oryginalnym przedstawione było jako po prostu brzydkie, w fiku stało się „niekonwencjonalne”, a przez to intrygujące. Kustritz zupełnie pomija też teksty stricte pornograficzne.

To samo robią Salmon i Symons, gdy odnotowują, że podobnie jak w romansie, seks w slashu służy fabule, a nie fabuła seksowi; dodatkowo współżycie ma miejsce tylko między osobami pozostającymi w stałym związku, które łączy jakaś emocjonalna więź, a związki oparte są na wyłączności, stąd w slashu często pojawia się motyw zazdrości o partnera. Jest to teza nie tyle fałszywa, co niepełna, wyklucza bowiem pokaźną liczbę tekstów, np. wszystkie fiki wykorzystujące motyw poliamorii. Rozgraniczenie między romansem a pornografią w przypadku slashu nie jest wcale takie łatwe. Często bowiem fabuła romansowa nie dominuje nad pornograficzną, ale też i pornograficzna nie przeważa nad romansową - są one ze sobą nieodłącznie powiązane. Właściwie zasadne byłoby podzielenie slashu na: bardziej romantyczny, bardziej pornograficzny i romantyczno-pornograficzny.

W przeciwieństwie do komercyjnego romansu, w którym najważniejszym elementem jest fabuła miłosna, slash może przedstawiać wątek miłosny jako poboczny. Anna Martuszewska w swojej analizie romansów odnotowuje co prawda przenikanie gatunku romansowego z innymi (głównie kryminałem), w ff jednak to przenikanie zdaje się zachodzić w drugą stronę - to nie romans przenika się np. z thrillerem, tylko thriller z romansem. Ponadto według Martuszewskiej gatunkiem, do którego romans nawiązuje najrzadziej jest science fiction, podczas gdy slash wykorzystuje go bardzo chętnie - w różnych odmianach - cyberpunk, steampunk, space opera itd. Slash byłby zatem gatunkiem, który chociaż wyewoluował z romansu, to przeszedł wiele niezależnych transformacji.Tym, co nadal łączy romans i slash, jest artykułowanie kobiecych lęków i nadziei ${ }^{13}$, jednakże w zupełnie odmienny sposób - romans głównie przez afirmację, slash - krytykę.

${ }^{12}$ C. Tosenberger, Homosexuality at the Online Hogwarts: Harry Potter Slash Fanfiction, „Children's Literature” 2008, s. 191.

${ }^{13}$ A. Martuszewska, J. Pyszny, Romanse z różnych sfer, Wrocław 2003, s. 7. 
Cechująca romans stereotypowość nie zawsze pojawia się w slashu. Na przykład postaci w ff są mniej typowe niż w romansie, ze względu na specyfikę tego gatunku („pożyczanie” gotowych bohaterów) posiadają bardziej rozbudowaną psychologię. W zasadzie fanki ochoczo przekształcają proste toposy, sięgają po tematy, których w klasycznym romansie nie ma - np. związek między gwiazdą porno a flufferem z fika Boy in the Angora Sweatervest ${ }^{14}$ anonimowej autorki (fandom filmu Incepcja), który wcale nie kończy się schematem Kopciuszka (w tym przypadku w wersji z Pretty Woman), a cała fabuła utrzymana jest w niepoważnym, lekkim tonie. Fanki sięgają po klasyczne narracje nie tylko po to, by opowiedzieć je na nowo, ale także by ukazać je z innej strony - opowiadanie Finding You Can Change ${ }^{15}$ autorstwa Hotsauce, inspirowane baśnią o Pięknej i Bestii, nie jest wcale historią miłości Pięknej i Bestii, lecz zaklętych wraz z Bestią służących - Świecznika i Zegara. Nie sprawdza się w fanfikcjach również i przedstawiony przez Martuszewską romansowy optymizm ${ }^{16}$ - czyli budowanie niemal idealnego świata („najlepszego z możliwych”). Wiele zaprezentowanych w ff rzeczywistości to typowe dystopie.

Według Janice Radway, romans pełni przede wszystkim dwie funkcje eskapistyczną i instruktażową ${ }^{17}$. Instruktażowość romansu wyraża się w tym, że poprzez lekturę czytelniczka poznaje świat. Instruktażowość slashu związana jest natomiast głównie z tym, co toczy się wokół lektury ff, stanowi raczej lekcję politycznej poprawności. Slash nie jest też stricte eskapistyczny. W swej lżejszej odmianie eliminuje co prawda chociażby problem seksizmu, ale luka, którą pozostawia, jest przecież znacząca. Russ twierdzi, iż w wielu ff występuje co jakiś czas przesadne wręcz podkreślanie, że bohaterowie są mężczyznami. Pisarki robią to według badaczki właśnie po to, aby nie dać się zdemaskować. Fantazja zostaje zatem zakłócona poprzez potrzebę podtrzymania jej. Pozycja obserwatorki z zewnątrz jest pozycją obserwatorki uświadomionej, która wie, dlaczego ogląda właśnie taki, a nie inny obraz.

Wiele fanfikcji występuje też przeciwko happy endowi. Takie najdrastyczniejsze przełamanie konwencji romansu stanowią tzw. darkfics - pełne przemocy lub hardcorowej pornografii bądź kombinacji obu. Nierzadko mieszają one ze sobą właśnie konwencję horroru i porno. Większość badaczy, szczególnie tych, którzy problematyką fan studies zajmują się „incydentalnie", zdaje się jednak nie natrafiać na takie fanfiction, gdyż ich opracowania milczą na ten temat.

${ }^{14}$ Anonimowa autorka, Boy in the Angora Sweatervest, http://inception-kink.livejournal.com/9327.html?thread=17353327\#t17353327 [dostęp 20.10.2014].

${ }^{15}$ Hotsauce, Finding You Can Change, http://archiveofourown.org/works/405883 [dostęp 20.10.2014].

${ }^{16}$ A. Martuszewska, J. Pyszny, Romanse z różnych sfer..., s. 103.

${ }^{17}$ J. A. Radway, Reading the Romance. Women, Patriarchy, and Popular Literature, Chapel Hill-London 1991, s. 104. 


\section{H/C, śmiech przez lzy}

Camille Bacon-Smith zauważa, że w klasycznym fiku typu hurt/comfort [krzywda/pocieszenie] występuje triada - zewnętrzny antagonista, który powoduje cierpienia, bohater [hero], który doświadcza cierpienia, i drugi bohater, który oferuje pocieszenie/opiekę. Slash tego typu pozwala fance-pisarce i czytelniczce wcielić się w dowolną rolę i albo odczuwać gniew antagonisty, albo empatię opiekuna, albo strach ofiary. Patriarchat zwyczajowo akceptuje publiczne odgrywanie jedynie roli opiekunki, kobiety nie mogą wyrażać gniewu, zwłaszcza skierowanego w stronę opresyjnej kultury, nie otrzymują też pocieszenia. Fiki h/c odrzucają zarazem wyidealizowany obraz śmierci, tym samym prze-pisują postać bohatera w taki sposób, że umieranie znów łączy się z bólem i cierpieniem, których doświadcza nie tylko ofiara, lecz i jej bliscy. Przywracając cierpieniu podmiotowość i tworząc opowieść wyrażającą to cierpienie, pisarki-fanki h/c powodują, że ból staje się realny, a agresor nie może mu już zaprzeczyćc ${ }^{18}$. Dlatego też według badaczki fiki hurt/comfort stanowią „,serce fandomu”.

Jednak takie przedstawienie slashu usuwa z niego zupełnie kontekst zabawy. Slash nie jest wcale aż tak poważny, jak chcą go widzieć badacze. Podczas gdy badacze pomijają kwestie humoru w fanfiction, fandom sam dekonstruuje się właśnie poprzez komizm. Wszystkie przytaczane przeze mnie terminy z fanowskiego słownika ukazują nie tylko samoświadomość fanek i to, jak wnikliwie fandom się analizuje, lecz oddają również jego poczucie humoru. Stosowane na początku fika nagłówki również pokazują, iż fanki mają świadomość, że ich teksty i pomysły są (bywają) absurdalne. Czasami wręcz specjalnie mnożą te absurdy, pisząc fiki, które mają zawrzeć w sobie jak najwięcej telewizyjnych stereotypów.

\section{Slash vs gay vs queer}

Na koniec należy także zastanowić się, czy skoro slash opowiada o relacjach homoerotycznych, jest on, lub może być, synonimem słowa gay. Ergo, czy to co „slashowe” jest również „homoseksualne”. Według części badaczek i badaczy, slashem nazwać można każdą erotyczną relację męsko-męską, według innych jednakże termin ten nie powinien być używany do określania związków, które są „kanoniczne”, czyli rzeczywiście homoseksualne. Slashem byłyby więc tylko relacje pozostające w sferze

${ }^{18}$ Cały ten akapit to parafraza poglądów badaczki. Por. C. Bacon-Smith, Enterprising Women. Television Fandom and the Creation of Popular Myth, Philadelphia 1992, S. $270-279$. 
podtekstu. Catherine Tosenberger dostrzega potencjalne niebezpieczeństwo w oddzielaniu slashu od narracji kanonicznie homoseksualnych: „[...] domaganie się, by slash wykraczał poza istniejący kanon, w problematyczny sposób przypisuje kanonowi heteronormatywność, której wcale nie musi posiadać. Co więcej, wzmacnia też przekonanie, że queerowe odczytania są zawsze odczytaniami narzuconymi z zewnątrz" ${ }^{19}$. Jednocześnie jednak część badaczy, szczególnie we wcześniejszych tekstach ff (z początku slashowego fandomu), odnotowała, że wiele fanek w ogóle nie traktuje slashu jako relacji homoseksualnej. Chociaż bohaterowie fików wchodzili w związki erotyczne z mężczyznami, to jednak sami nie identyfikowali się z tożsamością gejowską, nierzadko wykazując wręcz niechęć do tego, co „pedalskie” jako niemęskie i słabe. Protagoniści zakochiwali się w sobie niejako na przekór swojej seksualności. Taki slash często rozumiany był jako związek erotyczny między heteroseksualnymi mężczyznami („Moja standardowa definicja slashu to seksualny związek dwóch heteroseksualnych mężczyzn" - pisze Lezlie Shell ${ }^{20}$ ), których miłość przezwycięża ograniczenia płci. Dominowało przedstawienie relacji homoseksualnej jako pierwszej tego typu dla danego protagonisty, przy tym autorki-fanki ustami tegoż wielokrotnie podkreślały, że dany bohater „nie jest gejem, po prostu zakochał się w mężczyźnie”. W ten sposób, według Constance Penley, fanka-czytelniczka-pisarka nadal mogła sama nawiązywać seksualną relację z postaciami z fika. Jenkins podkreśla jednak, że taka praktyka ułatwiała też po prostu fankom wpasowywanie swojego opowiadania w kanon, który jednoznacznie pokazywał, że postaci uprzednio miały doświadczenia tylko ze związkami heteroseksualnymi ${ }^{21}$. Homofobiczne odrzucenie gejowskiej tożsamości jako gorszej zostało bardzo napiętnowane przez fandom, co nie oznacza oczywiście, że nie pojawiają się nadal teksty tego typu, stanowią jednak zdecydowaną mniejszość. Nie znaczy to również, że fandom jednoznacznie przestawił się na opisywanie doświadczenia homoseksualnego. Slash w zasadzie nadal nie jest skupiony na prezentowaniu realistycznego obrazu geja; daleko mu też do „klasycznej” literatury LGBT ${ }^{22}$. Bowiem same fanki często nie są ani nie były nigdy czytelniczkami tego typu powieści. Stąd slash rzadko sięga po charakterystyczne dla tej prozy tematy, takie jak chociażby AIDS, homofobia, coming out etc. Istnieją oczywiście

${ }^{19}$ C. Tosenberger, Homosexuality at the Online Hogwarts..., s. 187.

${ }^{20}$ Normal Female Interest in Men Bonking: Selections from The Terra Nostra Underground and Strange, Bedfellows, eds. S. Green, C. Jenkins, H. Jenkins, http://web.mit. edu/21fms/People/henry3/bonking.html [dostęp 13.10.2014].

${ }^{21}$ H. Jenkins, Textual Poachers: Television Fans and Participatory Culture (Studies in Culture and Communication), New York 1992 , s. 203-204.

${ }^{22}$ Być może slashowi bliżej jest do literatury lesbijskiej. Problem ten wymagałaby jednakże osobnej analizy. 
- jak zawsze - wyjątki - jak np. fanfik Coda ${ }^{23}$ autorstwa Raeschae, który opowiada historię ponownego nawiązania relacji między byłymi partnerami. Przyczyną rozstania protagonistów był fakt, że jeden z nich nie chciał wyjść z szafy (jak się później okazuje częściowo ze strachu - autorka przywołuje sprawę brutalnego morderstwa Matthew Sheparda). Obecnie slash odchodzi także od uznanego za problematyczne prostego przypisywania mężczyznom kobiecych atrybutów lub elementów androgynicznych. Wiele nowszych fanfików przedstawia bohaterów zbliżonych raczej do stereotypu macho. Ciekawy nurt tego typu stanowią nadal silnie rozwinięte wszystkie narracje dotyczące cop shows oraz te o superbohaterach. Częściowo slash nawiązuje do tzw. nurtu emancypacyjnego literatury LGBT, zasadniczo jednak homoseksualizm traktowany jest jako kontekst wtórny, a fantazje fanek domagają się raczej tekstów o protagonistach, którzy są gejami, jednakże same te teksty nie mają dotyczyć tylko problematyki gejowskiej. Musimy zastanowić się, czy w związku z tym slash nie jest de facto heteroseksistowski. Nie trudno bowiem zauważyć, że często fanfikcje slashowe fetyszyzują gejów, co także może (i powinno) wzbudzać niepokój. Dodatkowo do opisu relacji homoseksualnych fanki używają terminologii czy koncepcji stricte heteronormatywnych - do praktyk tych zalicza się m.in. jednoznaczne dzielenie postaci na top (partner aktywny, męski) i bottom (partner pasywny, kobiecy), gdzie seksualne preferencje stają się pewnym i nienaruszalnym wyznacznikiem charakteru, czy cały dyskurs tzw. prawdziwego seksu, czyli stosunku analnego (w przeciwieństwie do seksu, powiedzmy, „nieprawdziwego”, a więc wszystkich praktyk niezwiązanych z penetracją), który jest zwieńczeniem związku - pełnym ofiarowaniem się partnerowi. Taki stosunek jest wtedy oczywiście większym przeżyciem (nierzadko - utratą dziewictwa) dla „bottoma”, a akt opisany zostaje w tej samej konwencji, co heteroseksualny pierwszy raz. Również elementy męskiej anatomii zdają się bliższe w tym opisie ciału kobiety.

Jacek Kochanowski pisze, że „homoerotyczne pragnienie kobieco-kobiece zostało wprowadzone w orbitę heteroseksualnego pragnienia męskiego w postaci męskiej fantazji” ${ }^{24} \mathrm{i}$ wydaje się, że slash robi dokładnie

${ }^{23}$ Raeschae, Coda, http://raeschae.livejournal.com/39174.html [dostęp 1.11.2014]. Fik ten wykorzystuje zmiany nie tylko fokalizatora, lecz również przeplata wydarzenia z teraźniejszości ze wspomnieniami z przeszłości. Dodatkowo autorka wprowadza w tekst także inne formy literackie, jak korespondencje e-mail czy tekst jednego z protagonistów opublikowany przez niego później przypadkowo na stronie internetowej. Ponadto Coda napisana została jako odpowiedź na jedno z wyzwań literackich, opatrzona jest w związku z tym oryginalną grafiką, posiada też swoisty zwiastun filmowy. Fik ten stanowi poniekąd wzorcowy przykład twórczości fanowskiej.

${ }^{24}$ Zob. J. Kochanowski, Czy gej jest mężczyzną? Przyczynki do teorii postpłciowości, [w:] Gender. Konteksty, red. M. Radkiewicz, Kraków 2004. 
to samo z pragnieniem męsko-męskim, jednakże musimy pamiętać, że fantazje kobiece, podobnie jak kobieca rozkosz i pragnienie, po pierwsze - były tradycyjnie spychane na margines, kontrolowane przez patriarchat, po drugie - relacje mężczyźni homoseksualni - kobiety (powiedzmy) heteroseksualne nie są naznaczone tyloma problematycznymi konotacjami, co relacja pożądanie kobiece - męskie. Po trzecie zaś - kobiecy dyskurs slashu nie jest dyskursem ujarzmiającym. Nie chodzi w nim tylko o podniecenie, prawie zawsze bowiem fanka odczuwa emocjonalne zaangażowanie. Mówienie natomiast o tożsamości (tożsamościach) gejowskiej, którą trzeba by odpowiednio „przedstawic”, wprowadza problem tego, czy istnieje stała tożsamość seksualna, a więc i jakiś jej wzorzec, który można opowiedzieć. Poza tym, jeśli traktujemy slash jako kobiecą przestrzeń, pomysł, by mężczyzna zaczął tę przestrzeń zakłócać i ją korygować, jest sam w sobie dość problematyczny. Z drugiej jednak strony slash nie powinien uzurpować sobie prawa do utożsamienia z tym, co „homoseksualne”, bowiem zbyt łatwo wtedy o pominięcie jednostkowych doświadczeń i zupełnie osobistego aspektu bycia osobą queer. By nie być heteroseksistowski i heteronormatywny, slash musi zatem odrzucić element „gay”, zarazem jednak ustąpić mu pierwszeństwa. Lezlie Shell tak podsumowuje ten problem:

Jaka jest różnica między postaciami slashowymi a gejowskimi? Slashowi bohaterowie fascynują, ponieważ są przedłużeniem kobiecej seksualności, natomiast gejowscy, bo dają możliwość poznania obcej seksualności - tj. seksualności homoseksualnego mężczyzny. W pewien sposób chodzi tu o opozycję wewnętrzne vs. zewnętrzne. Pisarze i pisarki, którzy/które wolą postaci gejowskie, mają więcej punktów odniesienia, ponieważ pracują nad kulturą, która rzeczywiście istnieje - tj. kulturą homoseksualistów. Nie ma natomiast wyspy ze slashowymi mężczyznami ani socjologicznych opracowań opisujących ich zachowania. By odnaleźć, skąd pochodzi slash, musimy poszukać w sobie. Moje „zboczone” opowieści (te, których nigdy nie napiszę) to ciemne zakątki mej seksualności. Tematy, które opisuję - władza i zaufanie - dotyczą mnie jako kobiety, a nie Bodiego i Doyla jako pary gejów. Realizuję swoją fantazję erotyczną, a nie wiernie oddaję pragnienia homoseksualnych mężczyzn ${ }^{25}$.

Należy jednak podkreślić, że slashując heteroseksualny kanon, fanki zasadniczo przyznają, wbrew dominującym mechanizmom odczytania, pragnieniu queerowemu prawo istnienia tam, gdzie zostaje ono wykluczone z tekstu ${ }^{26}$. Ergo, to co odczytują fanki w podtekście, to opisane przez Eve Kosofsky Sedgwick ${ }^{27}$ męskie pragnienie homospołeczne. Fanki wyłuskują je z tekstu, lecz nie przekształcają go w pragnienie homoseksualne,

\footnotetext{
${ }^{25}$ Normal Female Interest in Men Bonking...

${ }^{26}$ I. Willis, Slash as Queer Utopia, http://ro.uow.edu.au/cgi/viewcontent.cgi?article= 1418\&context=lhapapers [dostęp 10.10.2014].

${ }^{27}$ E. Kosofsky Sedgwick, Between Men: English Literature and Male Homosocial Desire, New York 1985.
} 
ale raczej queerowe. Odkryty w ten sposób podtekst staje się najważniejszym kontekstem. Przy okazji podtekst ten daje fance niezwykłe poczucie władzy - przede wszystkim interpretowania wbrew oficjalnej „doktrynie”, zarazem zaś sugeruje, że jeśli nikt nie jest queer, każdy może być queer. Nie istnieje też model czy wzorzec, który fanka musiałaby czy to powielić, czy wpleść w swoją opowieść. Slash jest praktyką queerową wprowadzoną tylnymi drzwiami tam, skąd została wyparta.

\section{Genderswap, genderfuck, genderbend, genderqueer}

W slashu ukazane są mechanizmy opresji i wykluczenia, inne co prawda niż heteroseksizm czy homofobia, lecz i tak ustanawiające danego protagonistę w pozycji odmieńca, kogoś wolnego od wszelkiej normatywności, szczególnie jednak heteronormatywności, gdyż „heteronormatywność kultury oznacza, że podstawowym schematem interakcyjnym jest w niej pożądanie heteroseksualne" 28 .

Z tej perspektywy nawet jeśli rozumieć slash jako pisanie o kobietach w męskim ciele, czyli skupić się na tych jego odmianach, które prezentują bardziej androgynicznych lub kobiecych mężczyzn, możemy zaobserwować, że to tworzenie pseudokobiecego ciała w świecie, który pozytywnie waloryzuje jedynie prawdziwą męskość i wyszydza każdy przejaw kobiecości, samo w sobie staje się znaczące.

W tym aspekcie zdaje się, że pobrzmiewają tu echa dyskusji na temat aktów drag, które z jednej strony ukazują sztuczność i płynność, z drugiej, według wielu krytyków, podobnie jak camp - nie prowadzą do realnego czynu, rzeczywistej zmiany. Slash nie jest więc aktywizmem. Co więcej, to „przebieranie się” fanek w strój kobiecego mężczyzny jest - tak jak postuluje Judith Butler - odgrywaniem bez pierwotnego wzorca, gdyż to co powstaje, to fikcyjna tożsamość, która wykracza poza męską kulturę. Nie ma bowiem czegoś takiego jak podmiot slashowy.

Innym typem fików naruszających kategorie płci są tzw. genderswap, czyli narracje, $w$ których jeden z bohaterów na jakiś czas przybiera ciało kobiety. Ciekawe jest, że chociaż w zasadzie fiki te posiadają największy potencjał subwersywny, to niekoniecznie go wykorzystują. Alexis Lothian, która analizowała takie ff z perspektywy polityki queer $i$ trans, dostrzegła, że sposoby queerowania tekstu przez fanów bazują na schemacie romansowym, sam proces zmiany płci prezentowany jest natomiast z powtórzeniem kulturowych stereotypów kobiecości. W większości tych fików ciężar położono nie tyle na wierne oddanie tożsamości transpłciowej, co na

${ }^{28}$ Zob. J. Kochanowski, Czy gej jest mężczyzną?..., s. 104. 
analizę zmiany zachowania postaci i relacji między nimi. Jedynie nieliczne fanki przedstawiają ten schemat fabularny realistycznie, a nie jako seksualną fantazję. Autorka konkluduje jednak, że w tych nieadekwatnych obrazach z fanowskiej twórczości istnieje także pewien potencjał ${ }^{29}$ : „So even as many of the stories I've described here participate in narratives that we might find it easy to critique, their worldmaking projects may not always be so far from those of queer radicals" ${ }^{30}$. Ergo, warto podkreślić, że ff nawet jeśli nie wpisują się w pewne koncepcje (szczególnie te antysystemowe i aktywistyczne) całkowicie, to często oferują jednak i tak więcej niż oficjalny dyskurs. Zauważmy też, że wszystkie typy fanfikcji, które wykorzystywały motyw wielopłciowości, budowały napięcie między tym, co normalne, a tym co Inne, perwersyjne, zboczone. Wszystkie zarazem stanowiły formę poszukiwania jakiejś odmiennej płci/tożsamości, której nie ma. Już samo wprowadzenie do tekstów postaci fantastycznych i mitycznych oraz hybrydycznych innych, znamionuje queerowość, gdyż, jak pisze Harry M. Benshoff:

[...] w przypadku monster movies same elementy narracji domagają się przedstawienia „Inności”, która często bywa interpretowana (po stronie produkcji i/lub recepcji) jako tożsamość lesbijska, gejowską czy w inny sposób queerową. [...] [H]orrory i monster movies, być może bardziej niż jakikolwiek inny gatunek filmowy, aktywnie przywołują queerowe odczytania ze względu na swoje oczywiste metaforyczne (nierealistyczne) formy i struktury narracji, które zaburzają heteroseksualne status quo ${ }^{31}$.

Queer traktować zatem będziemy jako ogólną metaforę wyobcowania. Kontestację patriarchatu i heteroseksualnego pragnienia. Dlatego też możemy mówić o queerze i feminizmie w przypadku tekstów, które nie przedstawiają (bezpośrednio) ani kobiet, ani homoseksualistów. Slash jest queerowy, ponieważ daje możliwość porzucenia wszelkiej normatywności, przekroczenia płci w ogóle.

Temu służą wszystkie praktyki i operacje, których fanki dokonują na ludzkim (a czasami już nie-ludzkim) ciele - zmiany w ciało animalistyczne, genderfuck, dodawanie i zbieranie elementów anatomii, jak również

${ }^{29}$ Cały powyższy akapit jest luźnym tłumaczeniem tekstu Lothian. Zob. tejże, Doing Boys Like They're Girls, and Other (Trans)gendered Subjects: The Queer Subcultural Politics of 'Genderfuck', Fan Fiction, http://queergeektheory.wordpress.com/2008/10/12/doing-boys-like-they\%E2\%80\%99re-girls-and-other-transgendered-subjects-the-queer-subcultural-politics-of-\%E2\%80\%98genderfuck\%E2\%80\%99-fan-fiction/ [dostęp 15.10.2014].

${ }^{30}$ Należy zaznaczyć, że Lothian bada slash z perspektywy aktywizmu.

${ }^{31}$ Cyt. za: C. Tosenberger, „The Epic Love Story of Sam and Dean”: Supernatural, Queer Readings, and the Romance of Incestuous Fan Fiction, „Transformative Works and Cultures" 2008, t. 1, http://journal.transformativeworks.org/index.php/twc/article/ view/30/36 [dostęp 17.10.2014]. 
tożsamości - feminizowanie, odrealnianie, poddawanie się biologii, to uciekanie od stabilnej, jednolitej podmiotowości. To uciekanie od ciała, które jest nam przypisane, lecz jednak nadal często podlega kontroli zewnętrznej.

\section{Writing slash, rewriting culture}

\section{Summary}

'Fanfiction' is a term used for amateur, non-commercial stories written by fans, which relate to specific texts of culture. In my paper I make an attempt to analyze a special type of fanfiction, that is 'slash'. Several academics identify this genre with pornography, because it includes a plenty of short texts focusing on erotic scenes. There are also many long stories among them with complex plots arranged only to depict a sexual fetish that confirm this view. However, other researchers claim that the most important context for fanfiction is heterosexual romance, not porn. It is a popular strategy in fics to rewrite plots taken from romantic comedies, harlequins or even Disney's films and fairy tales, while replacing the original heroine with a male character from another text of culture.

On the basis of the very definition of slash I also ask a question whether 'slash' equals 'homosexual' - that is, whether slash is or may be considered gay literature. In fact, 'slash fiction' does not focus on the realistic depiction of gay people; it is also far from being LGBT literature. Although fans' fantasies demand texts about gay characters, it does not mean they are just about gay topics. 